\title{
Training Needs of Vocational Forestry Staff in Ogun State Nigeria.
}

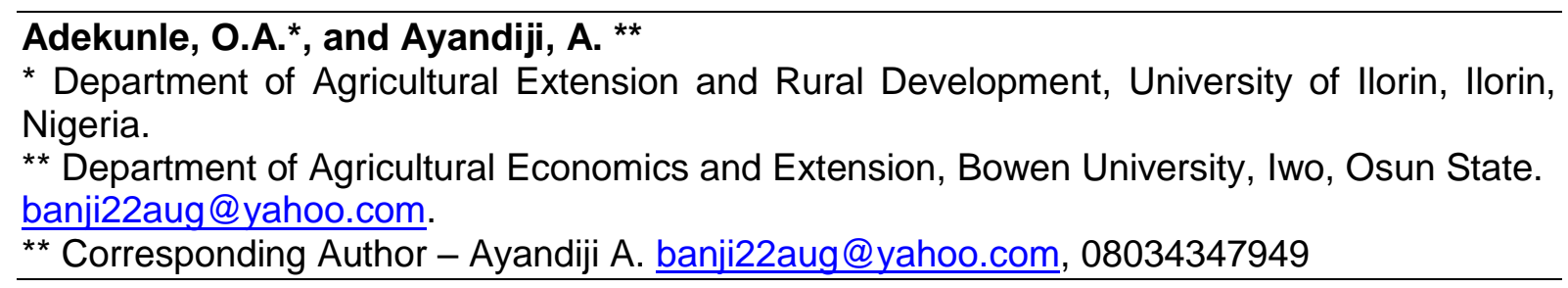

\section{Abstract}

Forests contribute in different forms to national and economic growths. Nigeria suffers the second largest net loss in forest reserve with 4.0 million hectares cleared annually. There is also inadequate training based on need assessment, and forestry personnel lack opportunities to update their knowledge. These concerns gave rise to this study with specific objectives to level of knowledge and level of skills of vocational staff in forestry activities. Data were collected using a simple random sampling technique in the selection of $50 \%$ of vocational staff totaling 143 respondents. Descriptive statistics and inferential statistics were used to analyze data. Majority of forestry vocational staff were between ages 41-50 years. Majority of vocational staff were school certificate holders and all staff considered themselves to be forest stakeholders. Thirty two percent of vocational staff attended Hammer procedure course. Vocational staff perceived their knowledge level and skill level as medium and that they needed little or no training in most of the area of needs. In conclusion, the study has shown that vocational staff in the study area needs to improve their knowledge, skills in forestry activities to meet up with the contemporary challenges.

Keywords:- Vocational staff, Training needs, Forestry Activities, Knowledge level, Skill level

\section{Introduction}

Forests contribute in different forms to national and economic growth, thereby, providing employment for the rural populace and serving as good conservers of soilwater. In addition, forests serve as habitation for wildlife biodiversity and provide food, recreational and aesthetic values to the environment. Unlike in the past, when forests were taken for granted, people are becoming increasingly aware of the direct and far-reaching influences of forests on the environment. Trees also help in breaking the forces of wind, thus preventing wind erosion. They therefore, serve as good conservers of soil water by encouraging percolation and discouraging run-off. Forest sub-sector accounts for about $8 \%$ of the agricultural gross domestic products (Gbadebo, et al, 2002) and several millions of households, therefore, depend on non-timber forest products (NTFPs) for subsistence purposes and income, (Etukudor, 2003).

Many state forest reserves in the country were originally set up in recognition of the importance of many tree species and the associated flora and fauna. Forestry is a 


\section{Journal of Agricultural Extension}

Vol. 17 (1) June, 2013

ISSN 1119-944X

source of revenue to government and the private sector. This is through the harvesting, processing and sale of forest produce- ranging from wood to non-wood forest produce. For example, between 1990 and 1994, Edo State government generated more than N62 million from Okomu Forest Reserve (Faleyimi and Arowosoge 2011). Furthermore, forestry revenue in Akwa Ibom State accounted for about 30 percent of the state's total internally generated revenue between 1988 and 1996 (Udo, 2002). However in some cases the public does not control entry into government forest reserves to harvest minor forest products such as tree leaves, barks and roots. Within these forests are many endemic plant species and some that are commercially valuable, like mahogany and other hardwoods. The destruction of forests for timber, cropland, wood, fuel, pasture and urbanization has had an impact on many poor rural families who depend on forest resources for fuel, fodder, food, medicine and housing. Therefore, the deterioration of forests has accelerated soil erosion, sedimentation of rivers, and increased flooding (Kio, et. al. 1992). Lack of knowledge, skilled and well-trained vocational staff in the study area is a major problem, hence developing programmes, teaching farmers on problem solving strategies, facilitating rural community development efforts and forest sustainability may be impossible.

According to Borich, a need is described as a discrepancy or gap between "what is", or the present state of affairs in relation to a group and situation of interest, and "what should be", or desired state of affairs (Witkin and Altschuld, 1995; 2000). Borich (1980) pioneered his methodological model in an effort to design such a survey instrument that would allow one to collect data that can be weighed and ranked in order of priority. By doing so, responses can be linked to a practical decision framework to improve a training program. Borich defined a training need as "a discrepancy between an educational goal and trainee performance in relation to this goal." He further suggested that training programmes could utilize his model by employing the two extreme positions: what is (the measured behaviors, skills, and competencies of trainees) and what should be (the goals of the training program).

The general objective of the study was to assess the perceived training needs of forestry workers in forestry activities in South west of Nigeria. The specific objectives were to;(1)examine the level of knowledge of vocational staff in forestry activities;(2) determine the level of skills of vocational staff in forestry activities; (3) determine the attitudes of vocational staff towards forestry activities; and (4)determine constraints to performance of vocational staff involved in forestry activities in the study area.

\section{Methodology}

Vocational staff involved in forestry activities in Ogun state, South West Nigeria constituted the target population. Simple random selections of $50 \%$ of vocational staff were selected from the state, totaling 143 respondents out of 286 . Descriptive statistics were used in analyzing the data. Knowledge Level: This variable was measured by assigning one to each activity mentioned, the maximum mean is 5 and the minimum is 1 . The mean were categorised into high knowledge (5-4), moderately knowledge (3.99-2.1) and low knowledge (2-1). (Koponiyi, 2003). 
Borich formula was used in calculating training needs. Randol and Larry (1988) in a study on identifying staff development needs of cooperative extension Faculty using a modified Borich Needs Assessment Model indicated that scores per training needs could theoretically range from +20 to -4 . Interpretation of the calculated scores is suggested as follows:

1. A topic which has a negative score would be considered inappropriate for use in developing in-service programmes since it resulted from a combination of a very low importance score, a very high knowledge score, or a very low opportunity score.

2. A topic with a score which is relatively close to zero also would not be considered appropriate since it would seem that existing knowledge of the topic, or the opportunity to use new knowledge, is equal to the respondents' perceived importance of the topic i.e., the respondents' existing knowledge is equal to the current opportunity to use information related to the topic.

3. Those topics having positive scores should be rank-ordered and programming would be planned around those having the highest values. Therefore, the higher the number, the greater the need for training.

\section{Results and Discussion}

\section{Respondents' Socioeconomic characteristics}

Table 1 shows that majority of the respondents $(87.41 \%)$ were male and $12.59 \%$ were female while majority $(41.26 \%)$ were within the age range of $41-50$ years in Ogun State. Majority $(74.13 \%)$ of the respondents were married. Forty-one percent of the respondents had 2 to 3 children, majority $(62.94 \%)$ of the vocational staff had SSCE/GCE certificate; $32.17 \%$ had been on the job for 1-5years. This gives an indication that most of the respondents were employed recently and may be facing challenges on the field if compared to older individuals. Majority $(71.33 \%)$ of the respondents had no area of specialization because they were not trained in forestry. Majority $(32.87 \%)$ of the respondents were exposed to short term training on tree identification and $32.17 \%$ for hammer procedure. 
Journal of Agricultural Extension

Vol. 17 (1) June, 2013

ISSN 1119-944X

Table 1:

Distribution of respondents Socio Economic Characteristics

\begin{tabular}{|c|c|c|}
\hline Socio Economic Characteristics & Frequency & Percentage \\
\hline \multicolumn{3}{|l|}{ Sex } \\
\hline Male & 125 & 87.41 \\
\hline Female & 18 & 12.59 \\
\hline Total & 143 & 100 \\
\hline \multicolumn{3}{|l|}{ Age } \\
\hline $20-30$ & 39 & 27.27 \\
\hline $31-40$ & 29 & 20.28 \\
\hline $41-50$ & 59 & 41.26 \\
\hline $51-60$ & 16 & 11.19 \\
\hline Total & 143 & 100 \\
\hline \multicolumn{3}{|l|}{ Marital Status } \\
\hline Single & 34 & 23.78 \\
\hline Married & 106 & 74.13 \\
\hline Divorced & 3 & 2.10 \\
\hline Total & 143 & 100 \\
\hline \multicolumn{3}{|l|}{ Number of children } \\
\hline $0-1$ & 42 & 29.37 \\
\hline $2-3$ & 60 & 41.96 \\
\hline $4-5$ & 32 & 22.38 \\
\hline $6-7$ & 8 & 5.59 \\
\hline $8-9$ & 1 & 0.70 \\
\hline Total & 143 & 100 \\
\hline \multicolumn{3}{|l|}{ Year in Service } \\
\hline $1-5$ years & 46 & 32.17 \\
\hline $6-10$ years & 30 & 20.98 \\
\hline $11-15$ years & 27 & 18.88 \\
\hline $16-20$ years & 19 & 13.28 \\
\hline $21-25$ years & 15 & 10.49 \\
\hline $26-30$ years & 6 & 4.2 \\
\hline 31 - 35years & 0 & 0 \\
\hline \multirow{2}{*}{\multicolumn{3}{|c|}{ Educational Qualification }} \\
\hline & & \\
\hline GCE/ SSCE & 90 & 62.94 \\
\hline Certificate & 9 & 6.29 \\
\hline OND & 34 & 23.78 \\
\hline NCE & 1 & 0.70 \\
\hline HND & 9 & 6.29 \\
\hline \multirow{2}{*}{\multicolumn{3}{|c|}{ In service Training }} \\
\hline & & \\
\hline Beat procedure & 4 & 2.80 \\
\hline Budding and grafting & 1 & 0.70 \\
\hline Forest law and policy & 3 & 2.10 \\
\hline Hammer procedure & 46 & 32.17 \\
\hline Log checking & 1 & 0.70 \\
\hline Monitoring patrol & 3 & 2.10 \\
\hline Nursery establishment & 8 & 5.59 \\
\hline Plantation establishment & 2 & 1.40 \\
\hline Plot demarcation & 5 & 3.50 \\
\hline Seed and Seedling tech & 2 & 1.40 \\
\hline Silvicultural Operation & $\overline{5}$ & 3.50 \\
\hline Survey & 3 & 2.10 \\
\hline Taxonomy & 13 & 9.09 \\
\hline Refresher course & 0 & 0 \\
\hline Tree identification & 47 & 32.87 \\
\hline Total & 143 & 100.00 \\
\hline \multicolumn{3}{|l|}{ Area of Specialization } \\
\hline General Agriculture & 0 & 0 \\
\hline Fisheries & 0 & 0 \\
\hline Horticulture & 1 & 0.70 \\
\hline Crop Science & 0 & 0 \\
\hline Soil Science & 2 & 1.40 \\
\hline Forestry & 36 & 25.17 \\
\hline Agric Extension & 2 & 1.40 \\
\hline Agric Economic & 0 & 0 \\
\hline Others & 102 & 71.33 \\
\hline Total & 143 & 100 \\
\hline
\end{tabular}




\section{Respondents perceived knowledge level}

Table 2 shows that Ogun State vocational staff have medium knowledge in forestry activities such as Techniques of plantation establishment and management $(\bar{x}=$ 3.434), basic measuration techniques $(\bar{x}=3.455)$, reporting forest defense and other development activities $(\bar{x}=3.846)$ etc. This gives an indication that the vocational staff were familiar with field operations and were performing at medium level while the perceived knowledge level in activities such as wildlife management and monitoring etc. were perceived as low. These areas were relatively new to these Vocational staff although, they may have received instructions on how to handle matters relating to such. They have, however not undergone training to that effect. The implication is that most of the vocational staff need training in the areas as listed in table2.

Table 2

Vocational staff perceived knowledge in Ogun State

\begin{tabular}{llll}
\hline knowledge varibles & WMA & SD & level \\
\hline Reporting forest offences and other development & 3.846 & 0.91 & $\mathrm{M}$ \\
activities & & & \\
Construct, maintain and operate a Forest nursery & 3.490 & 1.21 & $\mathrm{M}$ \\
Basic measuration techniques & 3.455 & 0.23 & $\mathrm{M}$ \\
Techniques of plantation establishment and management & 3.434 & 1.15 & $\mathrm{M}$ \\
Prevention of encroachment & 3.238 & 1.08 & $\mathrm{M}$ \\
Enforcement of environmental law & 3.077 & 1.23 & $\mathrm{M}$ \\
Prevention of accident & 2.951 & 1.05 & $\mathrm{~L}$ \\
Public awareness & 2.769 & 1.11 & $\mathrm{~L}$ \\
Wildlife management and monitoring & 2.490 & 1.17 & $\mathrm{~L}$ \\
Biodiversity monitoring and management & 2.357 & 1.07 & $\mathrm{~L}$ \\
\hline
\end{tabular}

Weighted Mean Average $=$ WMA SD $=$ Standard deviation

Where H- High, M-Medium, L- Low

Source: Field Survey, 2011

\section{Respondents perceived skills level}

Table 3 shows that respondents in Ogun State have a medium level of skills in checking forest offences $(\bar{x}=3.832)$; performing basic silvicultural techniques $(\bar{x}=$ 3.497 ) etc. while they had low level of skills in few areas. This may be due to the fact that the respondents were not able to put these skills to use because these activities were not their major areas but only useful for their field. 


\section{Table 3}

\section{Vocational staff perceived skills in Ogun State}

\begin{tabular}{llll}
\hline Skills & WMA & S D & level \\
\hline Tree Identification and tagging of tree & 3.867 & 1.152 & $\mathrm{M}$ \\
Checking forest Offence & 3.832 & 1.119 & $\mathrm{M}$ \\
Patrolling and detecting Offenders & 3.818 & 1.161 & $\mathrm{M}$ \\
Perform basic silvicultural techniques & 3.497 & 1.162 & $\mathrm{M}$ \\
On-field procedures and techniques & 3.441 & 0.924 & $\mathrm{M}$ \\
Safety Practices & 3.364 & 0.916 & $\mathrm{M}$ \\
Maintain of boundary lines and marks & 3.169 & 1.113 & $\mathrm{M}$ \\
Prevention of fire outbreak & 3.154 & 1.077 & $\mathrm{M}$ \\
Perform basic survey techniques & 3.126 & 1.119 & $\mathrm{M}$ \\
Monitoring and protecting of Natural resources & 3.077 & 0.986 & $\mathrm{M}$ \\
Perform basic harvesting techniques & 2.636 & 0.727 & $\mathrm{~L}$ \\
Ways and means of minimizing fuel wood consuming action & 2.538 & 0.803 & $\mathrm{~L}$ \\
Apply basic Principle of first aid & 2.042 & 1.027 & $\mathrm{~L}$ \\
\hline
\end{tabular}

Weighted Mean Average $=$ WMA SD $=$ Standard deviation

Where $\mathrm{H}$ - High, M-Medium, L- Low

Source: Field Survey, 2011

\section{Respondents' attitude towards forestry activities}

Table 4 shows that Ogun State respondents' attitude towards forestry activities is favourable $(\bar{x}=3.587)$ that is financial management in forestry is part of forestry, senior officers should not be concerned with administration $(\bar{x}=3.448)$, and junior officers are not expected to know anything in marketing of timber $(\bar{x}=3.225)$. This may be due to their level of understanding on administration in which their perception about financial management and administration is small. They also perceived that they were not lacking in technical ability, and site factors should be for specific people not all and because the skills involved in the job are lacking in some cadre of $\operatorname{staff}(\bar{x}=1.860)$. Record keeping should not be carried out every day $(\bar{x}=1.818)$; an indication that some were lazy to do the right thing. This current study shows that vocational staff in the study area do not have too strong attitude towards excellent forestry activities although they have a positive attitude which can be improved upon to give right and solid forestry activities in the state. 
Table 4

Vocational staff attitude towards forestry in Ogun State

\begin{tabular}{ll} 
Attitudinal statements & WMA \\
\hline Lack the technical competence in forestry activities & 2.392 \\
Financial Management in forestry is not part of forestry & $3.587^{*}$ \\
Site factors should be the job of all stakeholders in forestry & 1.860 \\
Record keeping should be done everyday & 1.818 \\
Forestry workers should be involved in providing seeds and & 1.713 \\
seedlings for farmers & \\
Senior officers should not be concerned with administration & $3.448^{*}$ \\
Junior officers are not expected to know anything in & $3.225^{*}$ \\
marketing of timber & \\
Pest and diseases control is more important in forestry than & 2.119 \\
in communication & \\
\hline Weighted Mean Average = WMA & \\
*Favourable & \\
Source: Field Survey, 2011 &
\end{tabular}

\section{Respondents perceived constraints}

Table 5shows that vocational staff in Ogun State perceived all the listed constraints as major constraints due to the fact that most of them were not new on the job, and may have earlier at one time or the other reported same to their supervisors. Some may even have dumped the job for other areas in the State because of these constraints when they were not attended to. These may have demoralized them to put their energy to work.

\section{Table 5}

Mean distribution of perceived constraints.

\begin{tabular}{lll}
\hline CONSTRAINTS & WMA & SD \\
\hline Poor Condition of service & 1.097 & 0.321 \\
High risk involved in forestry activities & 1.245 & 0.492 \\
Political Instability & 1.648 & 0.736 \\
No in-service training & 1.147 & 0.443 \\
Poor transportation within the forest zone & 1.042 & 0.201 \\
Insufficient knowledge about management techniques & 1.287 & 0.498 \\
Human wildlife conflict & 1.301 & 0.531 \\
Poor funding from the government & 1.035 & 0.184 \\
Problems of fire outbreak & 1.132 & 0.341 \\
Diseases and Pest infestation & 1.168 & 0.375 \\
Lack of Equipment & 1.007 & 0.084 \\
\hline Weigh
\end{tabular}

Weighted Mean Average $=$ WMA 


\section{Journal of Agricultural Extension}

Vol. 17 (1) June, 2013

ISSN 1119-944X

In the study area vocational staff training needs are less need because they were having negative scores or scores close to zero as seen in table 6 . This indicates that inappropriateness of the topic for training which is as a result of a combination of a very low importance score, a very high knowledge score, or a very low opportunity score or the opportunity to use new knowledge is equal to the respondents' perceived importance of the topic. The respondents' existing knowledge is equal to the current opportunity to use information related to the topic. Therefore, it is important that perceived new areas were explained to workers before embarking on training.

Table 6

Training needs of vocational staff in Ogun State.

\begin{tabular}{ll}
\hline Training Need & WMDS
\end{tabular}

\begin{tabular}{ll}
\hline $\begin{array}{l}\text { Reporting Forest offences and other development } \\
\text { activities }\end{array}$ & 0.38 \\
$\begin{array}{l}\text { Techniques of plantation establishment and } \\
\text { management }\end{array}$ & -0.32 \\
Construct, maintain and operate a forest Nursery & 0.318 \\
Basic measuration techniques mean & 0.9 \\
Prevention of encroachment & -0.56 \\
Prevention of accident & -2.02 \\
Public Awareness & -0.68 \\
Enforcement of environment Law & -0.106 \\
Biodiversity monitoring and management. & -0.04 \\
\hline
\end{tabular}

\section{Conclusion}

In conclusion, the level of knowledge of vocational staff was low in major forestry activities. The vocational staff were having medium level of skills. Therefore vocational staff in forestry activities must be properly trained in attitude, skill and knowledge to meet needs and ensure satisfactory standards of performance. Training on specific aspect of needs for forest workers will protect the forest reserve in the state.

\section{References}

Etukudo, I. (2003):"Botany, Conservational and Traditional Uses of Plants" The Verdict Press Uyo Pg $22-166$.

Faleyimi, O.I. and Arowosoge O.G.E (2011): Status of forest policy implementation in Kaduna State, Nigeria Austrian Journal of Basic and Applied Sciences 5(8):995-1001.

Gbadebo, O.A.; Oyesola, O.B. and Samuel, A.A. (2002): Gender Analysis of Income Generating Activities of Enclave Dwellers in Onigambari Forest Reserve of Oyo State. Proceedings of the 28th Annual Conference of the Forestry Association of Nigeria held in Akure, Ondo State. pp $233-238$. 


\section{Journal of Agricultural Extension}

Vol. 17 (1) June, 2013

ISSN 1119-944X

Kio, P.R.O., J.E. Abu and R. G. Lowe (1992): High Forest management in Nigeria Invited Paper for the IUFRO Centennial Conference, Eberswalde, Germany.

Kuponiyi F. A. (2003) involvement of private organisation in Agricultural Extension delivery in south western Nigeria Unpublished Ph. D. Thesis, University of lbadan pp $45-62$.

Randol G. W.,and Larry J. H. (1988) in a study on Identifying Staff Development Needs of Cooperative Extension Faculty Using a Modified Borich Needs Assessment Model Journal of Agricultural Education Pp26-32 